\title{
Nomophobia is Associated with Insomnia but Not with Age, Sex, BMI, or Mobile Phone Screen Size in Young Adults
}

\author{
Haitham Jahrami $\mathbb{D}^{1,2}$ \\ Mona Rashed ${ }^{1,2}$ \\ Maha M AIRasheed (1D ${ }^{3}$ \\ Nicola Luigi Bragazzi ${ }^{4}$ \\ Zahra Saif ${ }^{\prime}{ }^{\prime}$ \\ Omar Alhaj $\mathbb{D}^{5}$
}

Ahmed S BaHammam (iD) ${ }^{6,7}$

Michael V Vitiello ${ }^{8}{ }^{8}$

'Ministry of Health, Manama, Bahrain; ${ }^{2}$ Department of Psychiatry, College of Medicine and Medical Sciences, Arabian Gulf University, Manama, Bahrain; ${ }^{3}$ Department of Clinical Pharmacy, College of Pharmacy, King Saud University, Riyadh, Saudi Arabia; ${ }^{4}$ Department of Mathematics and Statistics, Laboratory for Industrial and Applied Mathematics (LIAM), York University, Toronto, ON, Canada; ${ }^{5}$ Department of Nutrition, Faculty of Pharmacy and Medical Sciences, University of Petra, Amman, Jordan; ${ }^{6}$ Department of Medicine, College of Medicine, University Sleep Disorders Center, King Saud University, Riyadh, I I 324, Saudi Arabia; ${ }^{7}$ The Strategic Technologies Program of the National Plan for Sciences and Technology and Innovation in the Kingdom of Saudi Arabia, Riyadh, Saudi Arabia; ${ }^{8}$ Psychiatry \& Behavioral Sciences, Gerontology \& Geriatric Medicine, and Biobehavioral Nursing, University of Washington, Seattle, WA, 98195-6560, USA

Correspondence: Haitham Jahrami Ministry of Health, Manama, Bahrain, P.O. Box: 12

Tel $+973 \quad 17286334$

Fax +973 17270637

Email hjahrami@health.gov.bh
Purpose: NOMOPHOBIA (NO MObile PHone PhoBIA) or problematic smartphone use is a psychological disorder in which people are afraid of being cut off from their mobile phones. Currently, there has been no direct assessment of mobile phone screen size in the home setting and its effect on nomophobia and related symptoms, such as insomnia. Thus, we investigated the association between nomophobia, insomnia, and mobile phone screen size in a young adult population in Bahrain.

Patients and Methods: Using a descriptive, cross-sectional design, we surveyed participants aged 18 to 35 between August and September 2020 using an online questionnaire. Participants completed demographic questions and questions about personal mobile phones, the Nomophobia Questionnaire (NMP-Q), and the Insomnia Severity Index (ISI). The mobile phone screen size was determined using an open-source online database. Crude and adjusted regression analyses were fitted to examine the associations between the study variables.

Results: A total of 549 individuals, 54\% females, were included in the final analyses. One hundred and fourteen participants (21\%) had severe nomophobia, and 81 (14\%) had clinical insomnia. A strong positive pair-wise linear association was observed between NMP-Q and ISI $\beta 0.15, P=0.001$. Age, sex, BMI, and mobile phone screen size showed no association with the NMP-Q.

Conclusion: Nomophobia is very prevalent in young adult men and women, and it is closely associated with insomnia, regardless of mobile phone screen size, suggesting that mobile phone screen size should not be used as a proxy for hazardous usage.

Keywords: blue light, insomnia, ISI, no mobile phone phobia, problematic smartphone use, sleep problems

\section{Introduction}

Smart mobile phones are increasingly being incorporated into daily life. The many perks they provide, such as personal diary, instant messaging and e-mail exchanges, music and video play, games, camera, and calculator, have transformed it from a status symbol to a necessity. ${ }^{1}$ Along with these benefits come problems such as nomophobia, particularly among young people and those individuals whose daily activities have been rendered dependent on smartphone use. ${ }^{2}$ Some examples of daily activities include work or studying, online shopping, making payments, entry passes, travel e-tickets, QR codes access, and many more.

The term nomophobia (no mobile phone phobia) describes an emerging digital and virtual societal disorder emanating from pathological anxiety of being without 
a mobile device. ${ }^{3-5}$ Nomophobia has been defined as a mental health condition resulting in illogical fear of being detached from or not being able to use a mobile phone due, for example, to the lack of signal or internet connectivity or drained battery. ${ }^{6}$ Four dimensions describe nomophobia: fear of not being able to interact with others promptly, concern about losing connection, concern with difficulty getting information quickly, and discomfort not having a mobile device with self. ${ }^{7}$ The heightened level of nervousness, fear, or anxiety crystallizes with the inability to communicate instantly. ${ }^{8,9}$

The condition has been linked to various mental health problems and poor functioning. ${ }^{10,11}$ Nomophobia is associated with sleep problems (primarily insomnia), ${ }^{6,12}$ depressive symptoms, ${ }^{10,13}$ anger problems, ${ }^{14}$ stress disorders, ${ }^{5}$ anxiety, ${ }^{5,10,13}$ hyperactivity and oppositional problems, ${ }^{5,15}$ poor self-esteem, ${ }^{16}$ poor quality of life, ${ }^{13,17}$ and poor academic performance. ${ }^{18-20}$

To date, the disorder has been studied primarily in students, ${ }^{13,21-27}$ especially those studying health sciences as undergraduates, mainly nursing, ${ }^{28,29}$ in which selfesteem, extraversion, conscientiousness, and emotional instability appeared to be associated with the disorder. ${ }^{30}$

A recent meta-analysis of twenty studies involving 12,462 participants documented that the prevalence of severe nomophobia is approximately $21 \%$ [95\% CI $16 \%$; $28 \%$ ], suggesting that the societal burden of the condition is significant. ${ }^{11}$

Although nomophobia research is still in its early phases, available evidence suggests that neither age nor sex is a significant moderator of nomophobia. ${ }^{11}$ A recent study also concluded that nomophobia is also present equally at the different educational stages. $^{22}$ Consequently, the presence of a person having nomophobia cannot be assumed based on age, sex, or education. ${ }^{11,22}$

With the rapidly expanding use of visual display technology in mobile phones and other modern household devices, concern has developed regarding the potential hazards emanating from their use. It is not easily discernible whether nomophobia originates from problematic smartphone use or pre-existing anxiety. ${ }^{5}$ Other potential risk factors associated with the current culture of mobile phone use, including the characteristic features of the phones themselves, have not yet been researched. For example, it is known that mobile phone screen light spectrum includes blue to green light and can inhibit melatonin activity, resulting in reduced drowsiness, trouble inducing sleep, and non-restorative sleep. ${ }^{31}$ These fears have probably been exacerbated by the increases in the brightness and sizes of screens employed in these devices, the number of screens in the environment, and increased exposure to short-wavelength visible light (ie, blue to green) emission from such screens in daily domestic use. ${ }^{32}$

Wibirama and Nugroho investigated the effect of screen size on immersion in video gamers ${ }^{33}$ and showed that mobile devices with larger screen sizes gave a more significant immersion experience than mobile phone devices with small screen sizes. Furthermore, it has been suggested that a larger screen size may attract more viewer attention and hence and may deliver more light. ${ }^{34}$

The COVID-19 pandemic increased the use of electronic devices, primarily smartphones, as a means of mitigating the negative effects of social isolation, and connecting with the world, all while protecting the need for social distancing. ${ }^{35-37}$ Thus, the number of studies reporting the harmful effects of excessive mobile devices on mental and physical health is steadily increasing. ${ }^{11,37}$

To date, there has been no direct assessment of mobile phone screen size in the home setting and its effect on nomophobia. We hypothesized that the nomophobia score is higher in people using larger mobile phone screens and that insomnia scores are higher in people using larger mobile phone screens. Therefore, this study was designed to assess the association between nomophobia, insomnia, and mobile phone screen size in young adults.

\section{Materials and Methods}

\section{Study Design and Setting}

The information for this study in Bahrain was gathered using a descriptive, cross-sectional research methodology. Data were collected between August - September 2020 using selfadministered, structured questionnaires distributed via instant message groups and social media ads. Participants were urged to forward the survey link to friends and family who might meet the eligibility requirements. Using social media channels to recruit the specified sample allowed access to a larger demographic and geographic catchment with less effort and at a lower cost than traditional face-to-face recruitment. ${ }^{38}$ To improve the standard of research design and documentation, the recommendations for Strengthening the Reporting of Observational Studies of Epidemiology $(\mathrm{STROBE})^{39}$ were implemented in this study. The Checklist for Reporting Results of Internet E-Surveys was used to create the electronic survey. ${ }^{40}$ The use of "mandatory" fields was used in our survey for all variables to eliminate missing data. 


\section{Participants and Sample Size}

A convenience non-probability sample of individuals between the ages of 18 and 35 defined as 'young adults', of both sexes, who owned at least one mobile device and was willing to participate in the study was included. Participants with a formal diagnosis of any mental illness were excluded using a brief screening, direct questioning skip logic algorithm. In addition, self-reports of receiving a physician's diagnosis or regular treatment for cardiovascular disease, chronic respiratory problems, diabetes mellitus, gastroesophageal reflux disease, neurological disorders, renal disease, and thyroid disease were excluded.

We estimated a minimum needed sample size of 384 participants to have $95 \%$ confidence that the real value would be within 5\% $\alpha$ (type I error) level and $20 \% \beta$ (type II error) level of the observations made. ${ }^{42}$

The following formula for the sample size $\mathrm{n}$, was used: $\mathrm{n} \mathrm{N} * \mathrm{X} /(\mathrm{X}+\mathrm{N}-1)$, where

$\mathrm{X} \mathrm{Z} \mathrm{Z}_{\alpha / 2}{ }^{2 *} \mathrm{p}^{*}(1-\mathrm{p}) / \mathrm{MOE}^{2} . \mathrm{Z}_{\alpha / 2}$ is the critical value of the Normal distribution at $\alpha / 2$ (eg, for a confidence level of $95 \%, \alpha$ is 0.05 , and the critical value is 1.96 ), MOE is the margin of error, $\mathrm{p}$ is the sample proportion, and $\mathrm{N}$ is the population size. ${ }^{42}$

\section{Ethical Considerations}

All processes were carried out under the Helsinki Declaration of 1964 and its modifications. The Bahraini Ministry of Health's Secondary Healthcare Research Ethics Committee (REC) evaluated and authorized this study (SHCRC/EF/14/10/2020). Written informed consent was sought and obtained from all participants before data collection.

\section{Data Sources and Measurement}

A structured survey was used to collect the data. The survey comprised demographic questions and questions about personal mobile phones, the Nomophobia Questionnaire (NMP-Q), and the Insomnia Severity Index (ISI).

\section{Sociodemographic and Anthropometric Measures}

The demographic questions included age, sex, selfreported body weight, self-reported body height, and the screening questions about physical and mental health. The BMI is expressed in kilograms per square meter $\left(\mathrm{kg} / \mathrm{m}^{2}\right)$, with a body mass in kilograms and height in meters, and was determined based on a person's weight and height by dividing the body mass by the square of the body height. BMI was categories as underweight $\leq 18.5 \mathrm{~kg} / \mathrm{m}^{2}$; normal weight $18.5-24.9 \mathrm{~kg} / \mathrm{m}^{2}$; overweight $25-29.9 \mathrm{~kg} / \mathrm{m}^{2}$; and obese $\geq 30 \mathrm{~kg} / \mathrm{m}^{2}$.

Participants were also asked to identify their primary mobile phone device manufacturer and model number. We identified the viewport, resolution, pixel density, and mobile phone screen size from a database of mobile devices. $^{43}$

\section{Nomophobia and Insomnia Measures}

The NMP-Q ${ }^{7}$ was used to assess the severity of nomophobia, defined as participants' phobia/anxiety of being without a smartphone or handheld mobile device. The NMP-Q contains 20 questions, each of which is rated on a 7-point Likertlike scale ranging from 1 ("strongly disagree") to 7 ("strongly agree"). ${ }^{7}$ The overall scoring is divided into four categories: $<20$ No Nomophobia; 21-59 Mild Nomophobia; 60-99 Moderate Nomophobia; and 100-140 Severe Nomophobia. The Arabic validated version of the NMP-Q was used in this study, and it has outstanding psychometric characteristics, with a Cronbach's alpha coefficient of $0.90 .{ }^{44}$

The $\mathrm{ISI}^{45}$ was used to assess the severity of diurnal and nocturnal insomnia symptoms. The ISI comprises seven questions that measure various facets of insomnia: difficulty falling or staying asleep, early awakenings, satisfaction with sleep efficiency, interfering with functioning, and anxiety associated with disturbed sleep. Each item is rated for the prior two weeks on a five-point Likert scale ( $0=$ no problem, $4=$ severe problem). Total scores of 0-7 represent no clinically relevant insomnia, 8-14 represent subthreshold insomnia, 15-21 represent clinical insomnia (moderate severity), and 22-28 represent clinical insomnia (severe). The ISI has excellent psychometric properties and has been validated in Arabic. ${ }^{46}$ ISI has a sensitivity of $86 \%$ and a specificity of $88 \%$, respectively. ${ }^{45}$ In clinical groups, an ISI score of 15 or higher is considered insomnia. ${ }^{45}$

\section{Statistical Analysis}

Descriptive statistics were used to identify and report the demographic characteristics of the subjects, personal mobile phone parameters, NMP-Q, and ISI scores. The arithmetic mean and standard deviation were reported for continuous variables, and for categorical variables, the frequency count and percentages were used.

The independent samples $t$-test was used to examine the difference between men and women regarding average mobile phone screen size, NMP-Q, and ISI scores. When applicable, Cohen's d was also reported as effect size and 
defined as a difference in means proportional to the pooled variation. Chi-square statistic $\left(\chi^{2}\right)$ was used to examine the differences between men and women regarding their mobile phone screen size preference.

To test if there are any statistically significant variations between the means (of age, BMI, NMP-Q, and ISI), a one-way analysis of variance (ANOVA) was employed using the groupings of mobile phone screen sizes.

Pearson's product-moment correlation coefficient was used to measure the degree to which two variables (NMP$\mathrm{Q}$ and ISI) correlate linearly and are presented as $r$. Regression analysis was used to estimate the association NMP-Q, ISI, and selected characteristics of the study participants. Univariate linear regression analysis was used to estimate the association between NMP-Q and ISI. Univariate logistic regression analysis was used to investigate the association between the dependent variables NMP-Q or ISI and age, male sex, BMI, and mobile phone screen size as independent variables. Logistic regression analysis was also used in a multivariate analysis to estimate the association between NMP-Q or ISI and mobile phone screen size after correcting for age, sex, and ISI to estimate NMP-Q or NMP-Q for estimating ISI.

Statistical significance was described as a p-value of less than 0.05 . The $\mathrm{R}$ statistical computing 4.1.0 packages were used to analyze the data.

\section{Results}

A total of 549 individuals (54\% females) were included in the final analyses. The mean age of the study participants was $27.33 \pm 4.83$ years. The mean BMI was $25.56 \pm$ $5.69 \mathrm{~kg} / \mathrm{m} 2$. About one-quarter $(23 \%)$ of the participants were obese. The mean NMP-Q was $77.05 \pm 17.80$, the mean ISI was $8.24 \pm 4.21$, and the mean mobile phone screen size was $5.50 \pm 0.50$ inches. Approximately $80 \%$ of the participants had a mild or moderate level of nomophobia. Insomnia was much less common, with $14 \%$ of participants meeting the ISI of $>15$ criteria for clinical insomnia. A total of 114 (21\%) participants had a severe level of nomophobia, and 81 (14\%) had clinical insomnia. The most common mobile phone screen size was 5.8 inch with approximately one-third of the sample owning a device of such size. Table 1 shows the descriptive statistics of the participants in the study.

Table 2 shows detailed differences in the study parameters by sex. Independent samples t-tests showed that: women had
Table I Descriptive Statistics of the Study Participants (n 549)

\begin{tabular}{|c|c|}
\hline Age, y & $27.33 \pm 4.83$ \\
\hline Body weight, kg & $69.22 \pm 14.92$ \\
\hline Body height, cm & $164.86 \pm 8.30$ \\
\hline $\mathrm{BMI}, \mathrm{kg} / \mathrm{m}^{2}$ & $25.56 \pm 5.69$ \\
\hline NMP-Q & $77.06 \pm 17.80$ \\
\hline ISI & $8.24 \pm 4.21$ \\
\hline MP screen size, INCH & $5.50 \pm 0.50$ \\
\hline MP pixel density, PPI & $480.01 \pm 90.05$ \\
\hline $\begin{array}{l}\text { Active MP data plan } \\
\text {-Yes }\end{array}$ & 549 (100\%) \\
\hline $\begin{array}{l}\text { Sex } \\
\text {-Male } \\
\text {-Female }\end{array}$ & $\begin{array}{l}253(46 \%) \\
296(54 \%)\end{array}$ \\
\hline $\begin{array}{l}\text { BMI Categories } \\
\text {-Underweight } \\
\text {-Normal weight } \\
\text {-Overweight } \\
\text {-Obese }\end{array}$ & $\begin{array}{l}42(8 \%) \\
215(39 \%) \\
168(31 \%) \\
124(23 \%)\end{array}$ \\
\hline $\begin{array}{l}\text { NMP-Q Categories } \\
\text {-No nomophobia } \\
\text {-Mild nomophobia } \\
\text {-Moderate nomophobia } \\
\text {-Severe nomophobia }\end{array}$ & $\begin{array}{l}\text { None }(0 \%) \\
35(6 \%) \\
400(73 \%) \\
114(21 \%)\end{array}$ \\
\hline $\begin{array}{l}\text { ISI Categories } \\
\text {-No clinically significant insomnia } \\
\text {-Subthreshold insomnia } \\
\text {-Clinical insomnia (moderate severity) } \\
\text {-Clinical insomnia (severe) }\end{array}$ & $\begin{array}{l}346(63 \%) \\
122(22 \%) \\
73(13 \%) \\
8(1 \%)\end{array}$ \\
\hline $\begin{array}{l}\text { MP screen size categories, inch } \\
-4.7 \text { inch } \\
-5.1 \text { inch } \\
-5.2 \text { inch } \\
-5.5 \text { inch } \\
-5.8 \text { inch } \\
-6.1 \text { inch } \\
-6.2 \text { inch } \\
-6.3 \text { inch } \\
-6.5 \text { inch }\end{array}$ & $\begin{array}{l}83(15 \%) \\
92(17 \%) \\
41(7 \%) \\
93(17 \%) \\
150(27 \%) \\
12(2 \%) \\
38(7 \%) \\
28(5 \%) \\
12(2 \%)\end{array}$ \\
\hline
\end{tabular}

Notes: Values are expressed as mean \pm standard deviation for continuous data or frequency count (percentage) for categorical data. BMI body mass index, underweight $\leq 18.5 \mathrm{~kg} / \mathrm{m} 2$; normal weight $18.5-24.9 \mathrm{~kg} / \mathrm{m} 2$; overweight $25-29.9 \mathrm{~kg} / \mathrm{m} 2$; and obese $\geq 30 \mathrm{~kg} / \mathrm{m} 2$. NMP-Q Nomophobia Questionnaire, $\leq 20$ no nomophobia, $21-59$ mild nomophobia, 60-99 moderate nomophobia, and 100-140 severe nomophobia. ISI Insomnia Severity Index, $\leq 7$ represents no clinically relevant insomnia, 8-14 represents subthreshold insomnia, 15-21 represents clinical insomnia (moderate), and 22-28 represents clinical insomnia (severe).

Abbreviations: MP, mobile phone; PPI, pixels per inch. 
Table 2 Differences in the Study Parameters According to Sex Grouping (n 549)

\begin{tabular}{|c|c|c|c|}
\hline Parameter & Male n 253 & Female n 296 & $P$-value \\
\hline NMP-Q & $76.03 \pm 17.00$ & $77.94 \pm 18.44$ & 0.21 \\
\hline ISI & $7.83 \pm 3.85$ & $8.58 \pm 4.48$ & 0.036 \\
\hline MP screen size, inch & $5.50 \pm 0.51$ & $5.49 \pm 0.49$ & 0.73 \\
\hline $\mathrm{BMI}, \mathrm{kg} / \mathrm{m}^{2}$ & $27.59 \pm 6.48$ & $23.83 \pm 4.20$ & 0.001 \\
\hline \multicolumn{4}{|l|}{ NMP-Q categories } \\
\hline -No nomophobia & None $(0 \%)$ & None $(0 \%)$ & 0.49 \\
\hline -Mild nomophobia & $16(6 \%)$ & $19(6 \%)$ & \\
\hline -Moderate nomophobia & $190(75 \%)$ & $210(71 \%)$ & \\
\hline -Severe nomophobia & 47 (19\%) & $67(23 \%)$ & \\
\hline \multicolumn{4}{|l|}{ ISI categories } \\
\hline -No clinically significant insomnia & 175 (69\%) & $|7|(58 \%)$ & 0.042 \\
\hline -Subthreshold insomnia & 48 (19\%) & $74(25 \%)$ & \\
\hline -Clinical insomnia (moderate severity) & 28 (11\%) & 45 (15\%) & \\
\hline -Clinical insomnia (severe) & $2(1 \%)$ & $6(2 \%)$ & \\
\hline \multicolumn{4}{|l|}{ MP screen size categories, inch } \\
\hline-4.7 inch & $43(17 \%)$ & $40(14 \%)$ & 0.80 \\
\hline-5.1 inch & $35(14 \%)$ & 57 (19\%) & \\
\hline-5.2 inch & $18(7 \%)$ & $23(8 \%)$ & \\
\hline-5.5 inch & $42(17 \%$ & 51 (I7\%) & \\
\hline-5.8 inch & 7I (28\%) & 79 (27\%) & \\
\hline-6.1 inch & $6(2 \%)$ & $6(2 \%)$ & \\
\hline-6.2 inch & 17 (7\%) & 21 (7\%) & \\
\hline-6.3 inch & $15(6 \%)$ & $13(4 \%)$ & \\
\hline-6.5 inch & $6(2 \%)$ & $6(2 \%)$ & \\
\hline
\end{tabular}

Notes: Values are expressed as mean \pm standard deviation for continuous data or frequency count (percentage) for categorical data. NMP-Q Nomophobia Questionnaire, $\leq 20$ no nomophobia, 2I-59 mild nomophobia, 60-99 moderate nomophobia, and I00-140 severe nomophobia. ISI Insomnia Severity Index, $\leq 7$ represents no clinically relevant insomnia, 8-14 represents subthreshold insomnia, 15-21 represents clinical insomnia (moderate), and 22-28 represents clinical insomnia (severe). MP mobile phone. PPI pixels per inch. Independent samples $t$-test for continuous data, and Chi-square statistic for categorical data. P-value was significant $<0.05$.

a statistically significant higher ISI score than men $P=0.036$, Cohen's d 0.20. However, men and women had similar NMP$\mathrm{Q}$ scores and mean mobile phone screen size. The mean mobile phone screen for men and women were $5.50 \pm 0.51$ and $5.49 \pm 0.49$, respectively, $P=0.73$, Cohen's d -0.03 . For the NMP-Q men and women scored $76.03 \pm 17.00$ and $77.94 \pm$ 18.44 , respectively, $P=0.21$, Cohen's d 0.11 . BMI was significantly higher in men compared to women, $27.59 \pm 6.48$ and $23.83 \pm 4.20$, respectively, $P=0.001$, Cohen's d -0.70 .

One-way ANOVA revealed no statistically significant difference in the means of age, BMI, NMP-Q, ISI by mobile phone screen size. Figure 1 shows the mean NMP-Q score by mobile phone screen size and Figure 2 shows the mean ISI score by mobile phone screen size.

A strong positive correlation was obtained between NMP-Q and ISI $r=0.63, P=0.001$. The results of examining the association between the NMP-Q and the ISI and selected features of the study participants are shown in Table 3. A strong positive pair-wise linear association was observed between NMP-Q and ISI, $\beta=0.15$, $P=0.001$. Age, sex, BMI, and mobile phone screen size showed no association with the NMP-Q.

\section{Discussion}

Our results showed that nomophobia is a modern-day virtual and digital society condition and refers to a pathological dread of being without mobile phone technology. The condition is highly prevalent among young adult men and women, strongly associated with clinically significant insomnia but unassociated with personal mobile phone screen size or obesity. However, many aspects of nomophobia's epidemiology, risk factors, psychological 


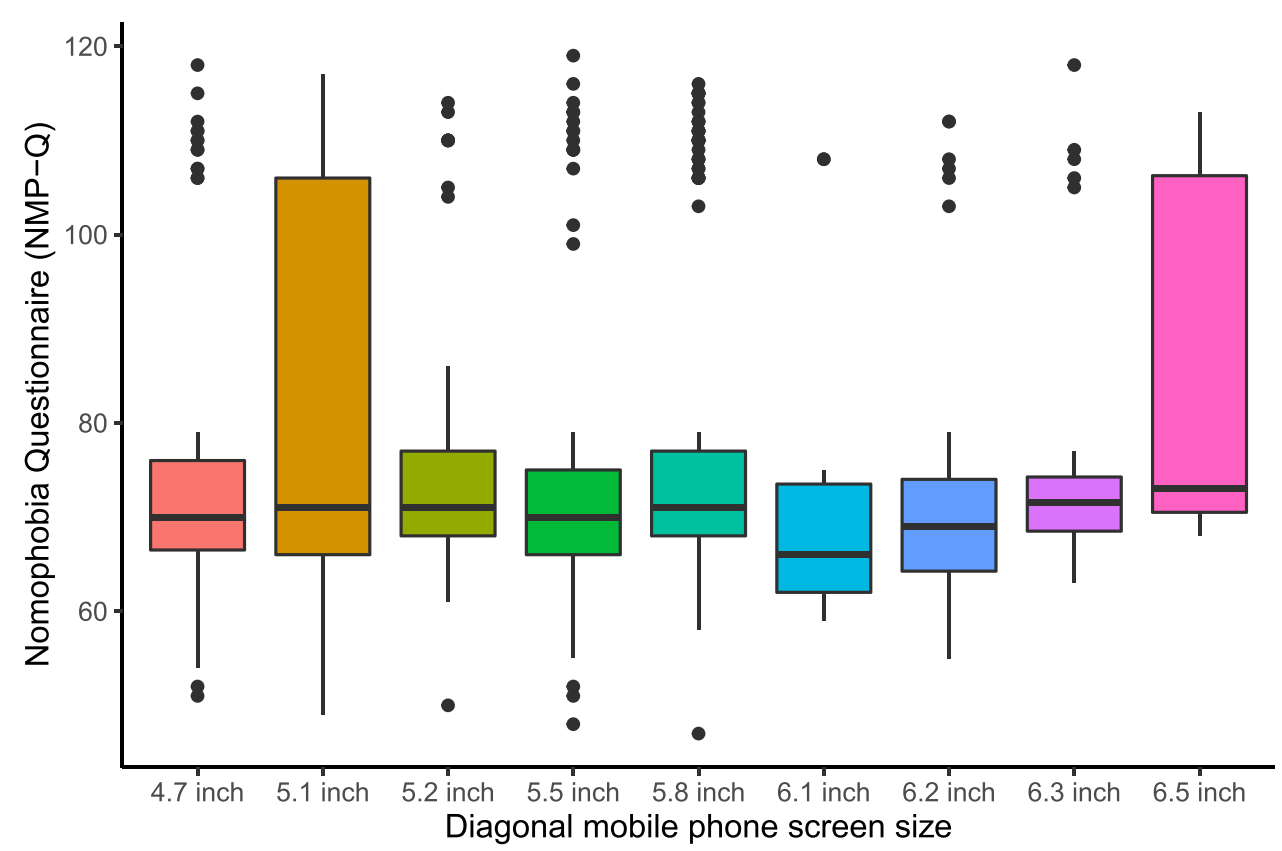

Figure I Mean Nomophobia Questionnaire (NMP-Q) score by mobile phone screen size.

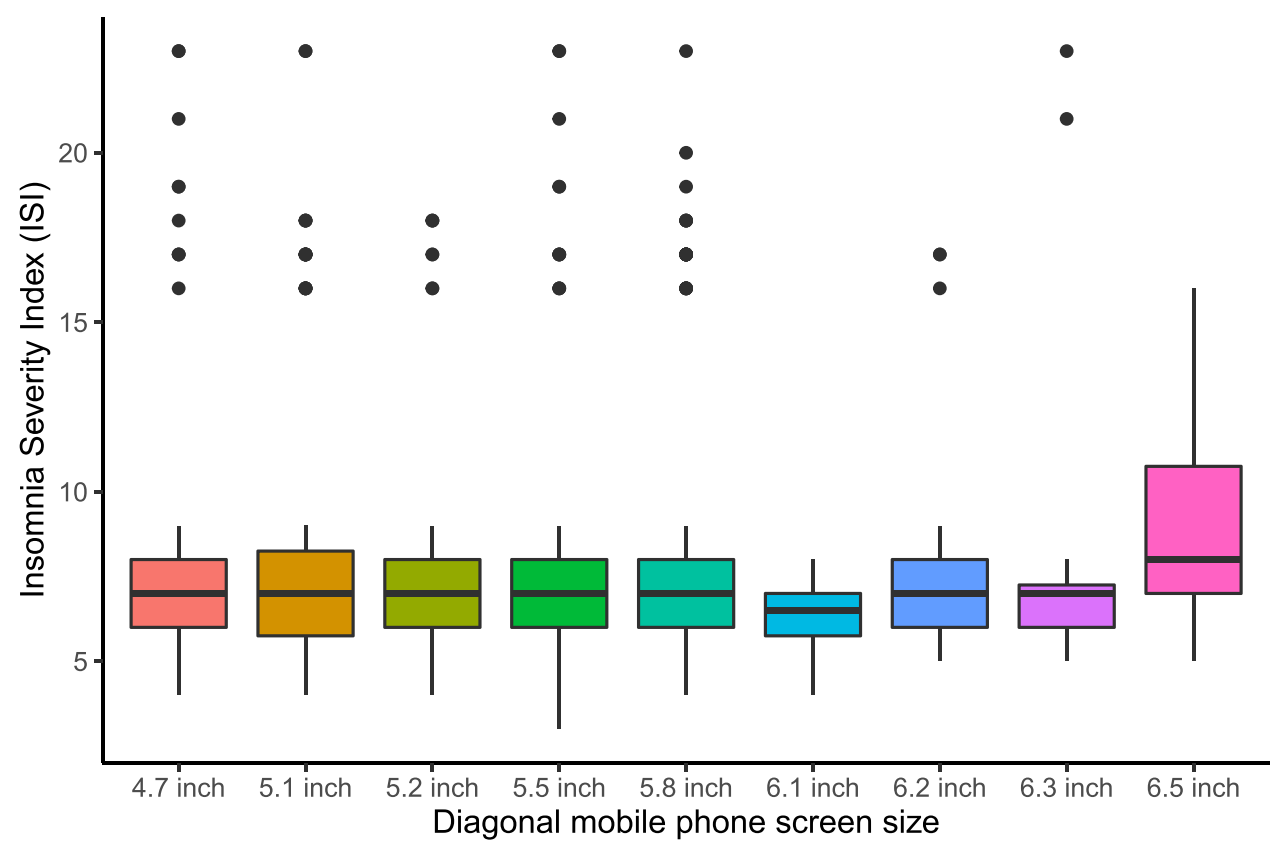

Figure 2 Mean Insomnia Severity Index (ISI) score by mobile phone screen size.

and behavioral characteristics are unclear. Therefore, research is strongly encouraged to better understand this condition.

Nomophobia symptoms are highly associated with insomnia symptoms in our study sample of young adults. This is in line with other research studies that have found a significant association between nomophobia and sleep difficulties. ${ }^{18,20,48-54}$ Several potential explanations have been put forward for the detrimental impact of smartphone use on sleep. First, continued smartphone usage, particularly before bedtime, lowers the amount of time spent sleeping, resulting in inadequate sleep. ${ }^{54}$ Second, some smartphone users prefer to spend their evenings browsing mobile websites. Users may experience anxiety and excitement as a result of inappropriate material on these websites, which might make it difficult to fall asleep due to 
Table 3 The Association NMP-Q, ISI and Selected Features of the Study Participants (n 549)

\begin{tabular}{|c|c|c|c|}
\hline \multicolumn{4}{|l|}{ Correlation Analysis } \\
\hline & & $r$ & $P$-value \\
\hline NMP-Q (Continuous) & ISI (Continuous) & 0.63 & 0.001 \\
\hline \multicolumn{4}{|l|}{ Regression analysis } \\
\hline \multicolumn{4}{|l|}{ Model I } \\
\hline Independent Variable & Dependent Variable & Estimate $\beta(95 \% \mathrm{Cl})$ & $P$-value \\
\hline NMP-Q (Continuous) & ISI (Continuous) & $0.15(0.13-0.17)$ & 00.001 \\
\hline \multicolumn{4}{|l|}{ Model 2} \\
\hline Age & $\begin{array}{l}\text { ISI } \\
\text { NMP-Q }\end{array}$ & $\begin{array}{l}1.00(0.96-1.06) \\
1.02(0.95-1.10)\end{array}$ & $\begin{array}{l}0.85 \\
0.53\end{array}$ \\
\hline Sex (Male) & $\begin{array}{l}\text { ISI } \\
\text { NMP-Q }\end{array}$ & $\begin{array}{l}0.65(0.40-1.05) \\
I .02(0.5 I-2.02)\end{array}$ & $\begin{array}{l}0.08 \\
0.96\end{array}$ \\
\hline BMI & $\begin{array}{l}\text { ISI } \\
\text { NMP-Q }\end{array}$ & $\begin{array}{l}0.98(0.94-1.03) \\
1.00(0.94-1.06)\end{array}$ & $\begin{array}{l}0.46 \\
0.92\end{array}$ \\
\hline MP screen size & $\begin{array}{l}\text { ISI } \\
\text { NMP-Q }\end{array}$ & $\begin{array}{l}0.80(0.50-1.28) \\
1.32(0.66-2.6 I)\end{array}$ & $\begin{array}{l}0.35 \\
0.43\end{array}$ \\
\hline \multicolumn{4}{|l|}{ Model 3} \\
\hline MP screen size & NMP-Q & $1.36(0.69-2.68)$ & 0.38 \\
\hline MP screen size & ISI & $0.54(0.25-1.16)$ & 0.12 \\
\hline
\end{tabular}

Notes: Correlation analysis is measure of linear association is denoted by the letter $r$, which is the Pearson product-moment coefficient. Regression analysis, reported estimates are $\beta$ coefficient for linear regression analysis and odds ratio for logistic regression analysis. Model I is univariate linear regression analysis. Model 2 is univariate logistic regression analysis. Model 3 multivariate logistic regression analysis correcting for age, sex and ISI for estimating NMP-Q or NMP-Q for estimating ISI. For models 2 and 3: ISI was categorized as insomnia ISI $\geq 15$ or healthy ISI $<$ I5. NMP-Q was categorized as moderate to severe nomophobia NMP-Q $\geq 60$ or mild nomophobia $<60$. MPSS mobile phone. P-value was significant $<0.05$.

emotional arousal. ${ }^{55}$ Third, two studies reporting morphological evidence from structural and functional magnetic resonance imaging that measured brain activity by detecting changes associated with blood flow showed changes in gray matter quantity and white matter integrity in young adults with nomophobia. ${ }^{56,57}$ Fourth, exposure to light and radiation from smartphone displays before bedtime may affect the start timing and secretion of melatonin, resulting in sleep-wake rhythm problems. ${ }^{58,59}$ A recent systematic review pointed that melatonin is suppressed by a two-hour exposure to blue light $(460 \mathrm{~nm})$ in the evening, with the shortest wavelengths having the most effect (424 nm, violet). ${ }^{60}$ Luckily, the melatonin levels rebounded quickly after the exposure ended, within 15 minutes, indicating a short-term or simultaneous effect of light exposure on melatonin production. Although melatonin production and suppression decrease with age, the light-induced circadian phase progression does not. The circadian phase of melatonin levels is influenced by light exposure in the evening, night, and morning. Furthermore, even the longest wavelengths (631 nm, red) and intermittent light exposure can adversely affect normal melatonin rhythmicity. ${ }^{60}$ Some solutions are now in the experimental phase; for example, a recent randomized clinical trial showed that wearing amber glasses lenses instead of clear lenses to block blue light for two hours before bedtime for a total period of one week resulted in better sleep and significantly reduced insomnia scores. ${ }^{31}$ From a biophysics perspective, the accessed content can modify the amount of blue light by modifying the average relative illuminance (ARI) in percent; for example, accessing a spreadsheet would allow ARI 90\% compared to a movie which allows ARI $20 \%{ }^{61}$ Thus, counseling individuals with insomnia on the timing, duration, and content of access to a smartphone, computer, and other device screens is a possibly effective intervention strategy.

The international commission on non-ionizing radiation protection (ICNIRP) is an independent organization 
that publishes various scientific information and sciencebased advice on non-ionizing radiation protection. The ICNIRP recommends limiting exposure time and, in certain circumstances, source size to minimize the harmful health effects from visible radiation on the eye and skin. ${ }^{62}$ In healthy young adults, exposure to blue light increases the activity of the prefrontal cortex (PFC), particularly the dorsolateral PFC (DLPFC) and ventrolateral PFC (VLPFC), which improves working memory and alertness while interfering with sleep. ${ }^{63}$ Blue light influences stress levels and may produce long-term insomnia symptoms by affecting certain glucocorticoid hormones, such as cortisol, and the sympathetic nervous system markers, such as $\alpha$ amylase. ${ }^{64}$

Our findings rejected our hypothesis, suggesting that the smartphone screen size was not an effect modifier of either nomophobia or insomnia. The explanations for the lack of association between screen size and insomnia are unclear. One possibility is that the viewing distance with larger screens may be more than that for smaller screens. ${ }^{34,65}$ While a television screen size is larger than a tablet screen, the distance one watches is generally much far from the larger screen. Thus, although a larger screen may emit more blue light, the viewing distance may counterbalance its impact. Moreover, a study that monitored eye movements to assess the total duration of eye fixation on the screen from participants playing video games demonstrated that the larger the screen size, the less the duration of fixation. Thus, the less duration of fixation may translate to less exposure to blue light. Therefore, further research in this area is needed in both laboratory and home environments to evaluate smartphone-generated light effects on the human circadian system.

Worldwide cohort research is looking into the longterm consequences of using mobile phones and other wireless technology for one's health; the COSMOS Study (Cohort Study of Mobile Phone Use and Health) concluded that insomnia in the highest users of mobile phones [62]. Besides blue light, mobile phones emit radiofrequency electromagnetic fields (RF EMF). The Australian radiation protection and nuclear safety agency recommend three changes to reduce mobile phone's RF EME exposure. ${ }^{66}$ First, increasing the distance between the mobile phone and your body. Second, reducing the time of exposure to mobile phones. Third, reducing the power by using the phone in an area with good reception and thus transmitting at considerably lower levels than in a reception-challenged location. ${ }^{66}$ While these suggestions were mainly targeted to reduce the RF EMF, we argue they may work on blue light too. Smartphone use may affect insomnia through multiple mechanisms, eg, blue light and RF EMF; thus, proper randomized controlled trials are needed to confirm this.

Our results suggest that nomophobia is not associated with age, sex, or BMI. According to a recent systematic review, nomophobia is more common in women, which reported that in 24 studies, women have nomophobia more than men, while eight studies found the reverse. ${ }^{10}$ Detailed inspection reveals that most of the studies finding women to have a higher prevalence of nomophobia were conducted in India and Turkey, compared with other Asian, European, and American countries. Thus, cultural diversity may explain this sex difference. Regarding age, most of the existing studies have a limited age range, which may affect subsequent interpretation. A recent systematic review showed that younger people are more susceptible to nomophobia. ${ }^{10}$ Our interpretation of the existing literature is that these findings are not mutually contradictory within age or sex but rather simply indicate that age and sex may be related to nomophobia in particular ways, impacted by cultural, economic, and logistical differences.

The major limitations of the study are: only young adults were sampled; convenience sampling was employed, and the self-reporting nature of the data collection process may all limit the generalizability of findings. We encourage future studies to employ objective measures approaches using, for example, commercial wearable devices (eg, smart bands, sleep trackers) to objectively monitor sleep and applications to monitor the frequency and duration of screen exposure throughout the day. Biophysics approaches can then estimate the daily dose of blue light for controlled analysis. In addition, future research might consider controlling for the use of prescription and blue light blocking eyewear.

Another delimitation of our work is the possible confounding effect of the COVID-19 pandemic on mobile phone use and/or sleep changes. It is also possible for methods of variance to overestimate the association between studied variables (nomophobia and insomnia). To illustrate, findings from a recent systematic review and meta-analysis showed that sleep problems are prevalent during the COVID-19 pandemic, affecting approximately $40 \%$ of the general population. ${ }^{67}$ Similarly, $50 \%$ of adults increased their screen time on at least two different devices during the pandemic to stay informed of important issues (eg, governmental directives). ${ }^{68}$ 
We recommend that future studies examine potentially problematic online activities (gambling, online gaming, pornography viewing, etc.) and their possible impact on problematic smartphone use.

\section{Conclusion}

Nomophobia is a modern-day virtual and digital society condition characterized by a pathological fear of being without mobile technology. The disorder is highly prevalent in young adult men and women, and it is closely associated with insomnia, regardless of the size of the mobile phone screen, indicating that the size of the mobile phone screen should not be used as a proxy for hazardous usage.

\section{Disclosure}

The authors report no conflicts of interest in this work.

\section{References}

1. Dasgupta P, Bhattacherjee S, Dasgupta S, Roy JK, Mukherjee A, Biswas R. Nomophobic behaviors among smartphone using medical and engineering students in two colleges of West Bengal. Indian J Public Health. 2017;61(3):199-204. doi:10.4103/ijph.IJPH_81_16

2. Csibi S, Griffiths MD, Demetrovics Z, Szabo A. Analysis of Problematic Smartphone Use Across Different Age Groups within the 'Components Model of Addiction'. Int $J$ Ment Health Addict. 2021;19(3):616-631. doi:10.1007/s11469-019-00095-0

3. Joyal CC. Defining "Normophilic" and "Paraphilic" Sexual Fantasies in a Population-Based Sample: on the Importance of Considering Subgroups. Sexual Med. 2015;3(4):321-330. doi:10.1002/sm2.96

4. Moser C, Kleinplatz PJ. Conceptualization, History, and Future of the Paraphilias. Annu Rev Clin Psychol. 2020;16:379-399. doi:10.1146/ annurev-clinpsy-050718-095548

5. Bhattacharya S, Bashar MA, Srivastava A, Singh A. NOMOPHOBIA: NO MObile PHone PhoBIA. J Family Med Primary Care. 2019;8 (4):1297-1300. doi:10.4103/jfmpc.jfmpc_71_19

6. Farchakh Y, Hallit R, Akel M, et al. Nomophobia in Lebanon: scale validation and association with psychological aspects. PLoS One. 2021;16(4):e0249890. doi:10.1371/journal.pone.0249890

7. Yildirim C, Correia A-P. Exploring the dimensions of nomophobia: development and validation of a self-reported questionnaire. Comput Human Behav. 2015;49:130-137. doi:10.1016/j.chb.2015.02.059

8. Moreno-Guerrero AJ, López-Belmonte J, Romero-Rodríguez JM, Rodríguez-García AM. Nomophobia: impact of cell phone use and time to rest among teacher students. Heliyon. 2020;6(5):e04084. doi:10.1016/j.heliyon.2020.e04084

9. Moreno-Guerrero AJ, Aznar-Díaz I, Cáceres-Reche P, RodríguezGarcía AM. Do Age, Gender and Poor Diet Influence the Higher Prevalence of Nomophobia among Young People? Int J Environ Res Public Health. 2020;17(10):3697. doi:10.3390/ijerph17103697

10. León-Mejía AC, Gutiérrez-Ortega M, Serrano-Pintado I, GonzálezCabrera J. A systematic review on nomophobia prevalence: surfacing results and standard guidelines for future research. PLoS One. 2021;16(5):e0250509. doi:10.1371/journal.pone.0250509

11. Humood A, Altooq N, Altamimi A, et al. The prevalence of nomophobia by population and by research tool: a systematic review, meta-analysis, and meta-regression. Psych. 2021;3(2):249-258. doi:10.3390/psych3020019
12. Jahrami H, Abdelaziz A, Binsanad L, et al. The association between symptoms of nomophobia, insomnia and food addiction among young adults: findings of an exploratory cross-sectional survey. Int J Environ Res Public Health. 2021;18(2):711. doi:10.3390/ijerph18020711

13. Sharma M, Amandeep Mathur DM, Jeenger J. Nomophobia and its relationship with depression, anxiety, and quality of life in adolescents. Ind Psychiatry J. 2019;28(2):231-236. doi:10.4103/ipj. ipj_60_18

14. Darvishi M, Noori M, Nazer MR, Sheikholeslami S, Karimi E. Investigating Different Dimensions of Nomophobia among Medical Students: a Cross-Sectional Study. Open Access Maced J Med Sci. 2019;7(4):573-578. doi:10.3889/oamjms.2019.138

15. Kuscu TD, Gumustas F, Rodopman Arman A, Goksu M. The relationship between nomophobia and psychiatric symptoms in adolescents. Int $J$ Psychiatry Clin Pract. 2021;25(1):56-61. doi:10.1080/13651501.2020.1819334

16. Servidio R. Fear of missing out and self-esteem as mediators of the relationship between maximization and problematic smartphone use. Curr Psychol. 2021. doi:10.1007/s12144-020-01341-8

17. Gonçalves S, Dias P, Correia A-P. Nomophobia and lifestyle: smartphone use and its relationship to psychopathologies. Computers Human Behav Rep. 2020;2:100025. doi:10.1016/j.chbr.2020.100025

18. Rodríguez-García AM, Moreno-Guerrero AJ, López Belmonte J. Nomophobia: an individual's growing fear of being without a smartphone-a systematic literature review. Int $J$ Environ Res Public Health. 2020;17(2):580. doi:10.3390/ijerph17020580

19. Wolfers LN, Festl R, Utz S. Do smartphones and social network sites become more important when experiencing stress? Results from longitudinal data. Comput Human Behav. 2020;109:106339. doi:10.1016/j.chb.2020.106339

20. Ahmed S, Pokhrel N, Roy S, Samuel AJ. Impact of nomophobia: a nondrug addiction among students of physiotherapy course using an online cross-sectional survey. Indian J Psychiatry. 2019;61(1):77-80. doi:10.4103/psychiatry.IndianJPsychiatry_361_18

21. Farooqui IA, Pore P, Gothankar J. Nomophobia: an emerging issue in medical institutions? $J$ Mental Health. 2018;27(5):438-441. doi:10.1080/09638237.2017.1417564

22. Rodríguez-García AM, Marín-Marín JA, López-Núñez JA, MorenoGuerrero AJ. Do Age and Educational Stage Influence No-MobilePhone Phobia? Int J Environ Res Public Health. 2021;18(9):4450. doi:10.3390/ijerph18094450

23. Mengi A, Singh A, Gupta V. An institution-based study to assess the prevalence of Nomophobia and its related impact among medical students in Southern Haryana, India. J Family Med Primary Care. 2020;9(5):2303-2308. doi:10.4103/jfmpc.jfmpc_58_20

24. Prasad M, Patthi B, Singla A, et al. Nomophobia: a Cross-sectional Study to Assess Mobile Phone Usage Among Dental Students. J Clin Diagnostic Res. 2017;11(2):Zc34-zc39. doi:10.7860/jcdr/2017/ 20858.9341

25. Cain J, Malcom DR. An Assessment of Pharmacy Students' Psychological Attachment to Smartphones at Two Colleges of Pharmacy. Am J Pharm Educ. 2019;83(7):7136. doi:10.5688/ ajpe 7136

26. Choudhury S, Saha I, Som TK, Ghose G, Patra M, Paul B. Mobile phone involvement and dependence among undergraduate medical students in a Medical College of West Bengal, India. J Educ Health Promot. 2019;8:1. doi:10.4103/jehp.jehp_134_18

27. Dixit S, Shukla H, Bhagwat A, et al. A study to evaluate mobile phone dependence among students of a medical college and associated hospital of central India. Indian j Community Med. 2010;35 (2):339-341. doi:10.4103/0970-0218.66878

28. Aguilera-Manrique G, Márquez-Hernández VV, Alcaraz-Córdoba T, Granados-Gámez G, Gutiérrez-Puertas V, Gutiérrez-Puertas L. The relationship between nomophobia and the distraction associated with smartphone use among nursing students in their clinical practicum. PLoS One. 2018;13(8):e0202953. doi:10.1371/journal.pone.0202953 
29. Moreno-Guerrero AJ, Hinojo-Lucena FJ, Trujillo-Torres JM, Rodríguez-García AM. Nomophobia and the influence of time to REST among nursing students. A descriptive, correlational and predictive research. Nurse Educ Pract. 2021;52:103025. doi:10.1016/j. nepr.2021.103025

30. Mir R, Akhtar M. Effect of nomophobia on the anxiety levels of undergraduate students. J Pak Med Assoc. 2020;70(9):1492-1497. doi:10.5455/jpma.31286

31. Shechter A, Kim EW, St-Onge M-P, Westwood AJ. Blocking nocturnal blue light for insomnia: a randomized controlled trial. $J$ Psychiatr Res. 2018;96:196-202. doi:10.1016/j.jpsychires.2017.10.015

32. Chaopu Y, Wenqing F, Jiancheng T, Fan Y, Yanfeng L, Chun L. Change of blue light hazard and circadian effect of LED backlight displayer with color temperature and age. Opt Express. 2018;26 (21):27021-27032. doi:10.1364/oe.26.027021

33. Wibirama S, Nugroho HA. Towards understanding addiction factors of mobile devices: an eye tracking study on effect of screen size. Annu Int Conf IEEE Eng Med Biol Soc. 2017;2017:2454-2457. doi:10.1109/EMBC.2017.8037353

34. McNiven MD, Krugman D, Tinkham SF. The big picture for large-screen television viewing. For Both Programming and Advertising, Audiences Are More Attentive, More Absorbed, and Less Critical. $J$ Advert Res. 2012;52:421-432. doi:10.2501/JAR-52-4-421-432

35. Cardy RE, Dupuis A, Anagnostou E, et al. Characterizing Changes in Screen Time During the COVID-19 Pandemic School Closures in Canada and Its Perceived Impact on Children With Autism Spectrum Disorder. Front Psychiatry. 2021;12:702774. doi:10.3389/fpsyt.2021.702774

36. Wagner BE, Folk AL, Hahn SL, Barr-Anderson DJ, Larson N, Neumark-Sztainer D. Recreational Screen Time Behaviors during the COVID-19 Pandemic in the U.S.: a Mixed-Methods Study among a Diverse Population-Based Sample of Emerging Adults. Int J Environ Res Public Health. 2021;18(9):4613. doi:10.3390/ ijerph 18094613

37. Esper MV, Araújo JS, Santos MAD, Nascimento LC. Nursing as a mediator between nomophobia and social isolation in response to COVID-19. Rev Gaucha Enferm. 2021;42(spe):e20200292. doi:10.1590/1983-1447.2021.2020-0292

38. McRobert CJ, Hill JC, Smale T, Hay EM, van der Windt DA. A multi-modal recruitment strategy using social media and internet-mediated methods to recruit a multidisciplinary, international sample of clinicians to an online research study. PLoS One. 2018;13 (7):e0200184. doi:10.1371/journal.pone.0200184

39. von Elm E, Altman DG, Egger M, et al. Strengthening the Reporting of Observational Studies in Epidemiology (STROBE) statement: guidelines for reporting observational studies. BMJ. 2007;335 (7624):806-808. doi:10.1136/bmj.39335.541782.AD

40. Eysenbach G. Improving the quality of Web surveys: the Checklist for Reporting Results of Internet E-Surveys (CHERRIES). J Med Internet Res. 2004;6(3):e34. doi:10.2196/jmir.6.3.e34

41. Palmiero M, Nori R, Piccardi L. Verbal and visual divergent thinking in aging. Exp Brain Res. 2017;235(4):1021-1029. doi:10.1007/ s00221-016-4857-4

42. Daniel WW, Cross CL. Biostatistics: A Foundation for Analysis in the Health Sciences. Wiley; 2018.

43. Screen Sizes: viewport Sizes and Pixel Densities for Popular Devices. Available from: https://screensiz.es/. Accessed October 23, 2021.

44. Al-Balhan EM, Khabbache H, Watfa A, Re TS, Zerbetto R, Bragazzi NL. Psychometric evaluation of the Arabic version of the nomophobia questionnaire: confirmatory and exploratory factor analysis - implications from a pilot study in Kuwait among university students. Psychol Res Behav Manag. 2018;11:471-482. doi:10.2147/ PRBM.S169918

45. Morin CM, Belleville G, Bélanger L, Ivers H. The Insomnia Severity Index: psychometric indicators to detect insomnia cases and evaluate treatment response. Sleep. 2011;34(5):601-608. doi:10.1093/sleep/ 34.5.601
46. Suleiman KH, Yates BC. Translating the insomnia severity index into Arabic. J Nurs Scholarsh. 2011;43(1):49-53. doi:10.1111/j.15475069.2010.01374.x

47. R. 4.1.0. Updated 2021. Available from: https://www.R-project.org/. Accessed January 6, 2020.

48. Jahrami H, Al-Mutarid M, Penson PE, Saif Z, Hammad L. Intake of Caffeine and Its Association with Physical and Mental Health Status among University Students in Bahrain. Foods. 2020;9(4):473. doi: $10.3390 /$ foods 9040473

49. Jilisha G, Venkatachalam J, Menon V, Olickal JJ. Nomophobia: a Mixed-Methods Study on Prevalence, Associated Factors, and Perception among College Students in Puducherry, India. Indian $J \quad$ Psychol Med. 2019;41(6):541-548. doi:10.4103/ijpsym. Ijpsym_130_19

50. Veerapu N, Philip RKB, Vasireddy H, Gurrala S, Kanna ST. A study on nomophobia and its correlation with sleeping difficulty and anxiety among medical students in a medical college, Telangana. Int J Community Med Public Health. 2019;6(5):2074-2076. doi:10.18203/2394-6040.ijcmph20191821

51. Sahin S, Ozdemir K, Unsal A, Temiz N. Evaluation of mobile phone addiction level and sleep quality in university students. Pak J Med Sci. 2013;29(4):913-918. doi:10.12669/pjms.294.3686

52. Daei A, Ashrafi-Rizi H, Soleymani MR. Nomophobia and Health Hazards: smartphone Use and Addiction Among University Students. Int J Prev Med. 2019;10:202. doi:10.4103/ijpvm.IJPVM_184_19

53. Demirci K, Akgönül M, Akpinar A. Relationship of smartphone use severity with sleep quality, depression, and anxiety in university students. $J$ Behav Addict. 2015;4(2):85-92. doi:10.1556/ 2006.4.2015.010

54. Huang Q, Li Y, Huang S, et al. Smartphone Use and Sleep Quality in Chinese College Students: a Preliminary Study. Original Research. Front Psychiatry. 2020;11(352). doi:10.3389/fpsyt.2020.00352

55. Belsare VH, Munghate SC, Tadas A, Belsare H, Agrawal S. Impact of Smart Phone usage on Sleep, Melatonin and its Correlation with Anxiety and Depression in First Year Medical Students. Innovative J Med Health Sci. 2020;10(07):254.

56. Wang Y, Zou Z, Song H, et al. Altered Gray Matter Volume and White Matter Integrity in College Students with Mobile Phone Dependence. Original Research. Front Psychol. 2016;7(597). doi:10.3389/fpsyg.2016.00597

57. Horvath J, Mundinger C, Schmitgen MM, et al. Structural and functional correlates of smartphone addiction. Addict Behav. 2020;105:106334. doi:10.1016/j.addbeh.2020.106334

58. Wood AW, Loughran SP, Stough C. Does evening exposure to mobile phone radiation affect subsequent melatonin production? Int $J$ Radiat Biol. 2006;82(2):69-76. doi:10.1080/09553000600599775

59. Liu S, Wing YK, Hao Y, Li W, Zhang J, Zhang B. The associations of long-time mobile phone use with sleep disturbances and mental distress in technical college students: a prospective cohort study. Sleep. 2019;42(2). doi:10.1093/sleep/zsy213

60. Tähkämö L, Partonen T, Pesonen AK. Systematic review of light exposure impact on human circadian rhythm. Chronobiol Int. 2019;36(2):151-170. doi:10.1080/07420528.2018.1527773

61. Bullough JD, Peana S, Camardello SJ. 73-4: invited Paper: are Displays Giving Us the Blues? SID Symposium Digest Tech Papers. 2020;51(1):1098-1101. doi:10.1002/sdtp.14066

62. ICNIRP | visible Light $(380-780 \mathrm{~nm})$. Available from: https://www. icnirp.org/en/frequencies/visible/index.html. Accessed January 6, 2020.

63. Alkozei A, Smith R, Pisner DA, et al. Exposure to Blue Light Increases Subsequent Functional Activation of the Prefrontal Cortex During Performance of a Working Memory Task. Sleep. 2016;39 (9):1671-1680. doi:10.5665/sleep.6090

64. Figueiro MG, Rea MS. The effects of red and blue lights on circadian variations in cortisol, alpha amylase, and melatonin. Int J Endocrinol. 2010;2010:829351. doi:10.1155/2010/829351 
65. Lombard M, Ditton TB, Grabe ME, Reich RD. The role of screen size in viewer responses to television fare. Commun Rep. 1997;10:95-106. doi:10.1080/08934219709367663

66. ARPANSA. How to reduce exposure from mobile phones and other wireless devices. Available from: https:/www.arpansa.gov.au/under standing-radiation/radiation-sources/more-radiation-sources/redu cing-exposure-to-mobile-phones. Accessed January 6, 2020.
67. Jahrami H, BaHammam AS, Bragazzi NL, Saif Z, Faris M, Vitiello MV. Sleep problems during the COVID-19 pandemic by population: a systematic review and meta-analysis. J Clin Sleep Med. 2021;17(2):299-313. doi:10.5664/jcsm.8930

68. Colley RC, Bushnik T, Langlois K. Exercise and screen time during the COVID-19 pandemic. Health Rep. 2020;31(6):3-11. doi:10.25318/82-003-x202000600001-eng

\section{Publish your work in this journal}

Nature and Science of Sleep is an international, peer-reviewed, open access journal covering all aspects of sleep science and sleep medicine, including the neurophysiology and functions of sleep, the genetics of sleep, sleep and society, biological rhythms, dreaming, sleep disorders and therapy, and strategies to optimize healthy sleep.
The manuscript management system is completely online and includes a very quick and fair peer-review system, which is all easy to use. Visit http://www.dovepress.com/testimonials.php to read real quotes from published authors. 